OPEN ACCESS

Edited by:

Vittorio Capozzi,

University of Foggia, Italy

Reviewed by:

Ainhoa Revilla-Guarinos,

Technische Universität Dresden,

Germany

Kiiyukia Matthews Ciira,

Mount Kenya University, Kenya

*Correspondence:

Gwénaël Jan

gwenael.jan@inra.fr

tThese authors share senior authorship

Specialty section: This article was submitted to

Food Microbiology,

a section of the journal

Frontiers in Microbiology

Received: 19 April 2018 Accepted: 05 October 2018 Published: 22 October 2018

Citation:

Huang S, Gaucher F, Cauty C, Jardin J, Le Loir Y, Jeantet $R$, Chen XD and Jan G (2018) Growth in Hyper-Concentrated Sweet Whey

Triggers Multi Stress Tolerance and Spray Drying Survival in Lactobacillus casei BL23: From the Molecular Basis to New Perspectives for Sustainable Probiotic Production. Front. Microbiol. 9:2548. doi: 10.3389/fmicb.2018.02548

\section{Growth in Hyper-Concentrated Sweet Whey Triggers Multi Stress Tolerance and Spray Drying Survival in Lactobacillus casei BL23: From the Molecular Basis to New Perspectives for Sustainable Probiotic Production}

\author{
Song Huang 1,2, Floriane Gaucher',3, Chantal Cauty², Julien Jardin², Yves Le Loir², \\ Romain Jeantet ${ }^{1,2 \dagger}$, Xiao Dong Chen ${ }^{1 \dagger}$ and Gwénaël Jan ${ }^{2 \star \dagger}$ \\ 'Suzhou Key Laboratory of Green Chemical Engineering, School of Chemical and Environmental Engineering, College \\ of Chemistry, Chemical Engineering and Material Science, Soochow University, Jiangsu, China, ${ }^{2}$ UMR1253 STLO, \\ Agrocampus Ouest, INRA, Rennes, France, ${ }^{3}$ Bioprox, Levallois-Perret, France
}

Lactobacillus casei BL23 has a recognized probiotic potential, which includes immune modulation, protection toward induced colitis, toward induced colon cancer and toward dissemination of pathogens. In L. casei, as well as in other probiotics, both probiotic and technological abilities are highly dependent (1) on the substrate used to grow bacteria and (2) on the process used to dry and store this biomass. Production and storage of probiotics, at a reasonable financial and environmental cost, becomes a crucial challenge. Food-grade media must be used, and minimal process is preferred. In this context, we have developed a "2-in-1" medium used both to grow and to dry L. casei BL23, considered a fragile probiotic strain. This medium consists in hyperconcentrated sweet whey (HCSW). L. casei BL23 grows in HCSW up to 30\% dry matter, which is 6 times-concentrated sweet whey. Compared to isotonic sweet whey (5\% dry matter), these growth conditions enhanced tolerance of $L$. casei BL23 toward heat, acid and bile salts stress. HCSW also triggered intracellular accumulation of polyphosphate, of glycogen and of trehalose. A gel-free global proteomic differential analysis further evidenced overexpression of proteins involved in pathways known to participate in stress adaptation, including environmental signal transduction, oxidative and metal defense, DNA repair, protein turnover and repair, carbohydrate, phosphate and amino acid metabolism, and in osmoadaptation. Accordingly, HCSW cultures of L. casei BL23 exhibited enhanced survival upon spray drying, a process known to drastically affect bacterial viability. This work opens new perspectives for sustainable production of dried probiotic lactobacilli, using food industry by-products and lowering energy costs.

Keywords: osmoregulation, probiotics, lactic acid bacteria, stress response, physiology, label-free proteomics, spray-drying 


\section{INTRODUCTION}

Lactobacillus is a major genus of the lactic acid bacteria (LAB), a GRAS (Generally Recognized as Safe) and economically important bacterial group used in foods, beverages, or dietary supplements. Lactobacillus casei is a facultative heterofermentative species usually used as a starter culture for milk fermentation and for the maturation of cheeses in the food industry (Hammes and Hertel, 2006). Selected certain strains of Lactobacillus casei can be used as probiotics (Hill et al., 2018). Promising data suggest a beneficial impact on several disorders in humans and in animals (Klaenhammer et al., 2012; Aktas et al., 2016).

Lactobacillus casei BL23, as an example, is a well-characterized probiotic. Its immunomodulatory properties were demonstrated in vitro (Bäuerl et al., 2011) and in vivo (Rochat et al., 2007; Lenoir et al., 2016; Cortes-Perez et al., 2017; Maiga et al., 2017; Qin et al., 2018). Its surface-exposed components were proposed to take part in interactions with the intestinal mucosa (Muñoz-Provencio et al., 2011; Qin et al., 2017), in inhibition of Staphylococcus aureus internalization (Bouchard et al., 2013; Souza et al., 2017), and in the metabolism of human milk oligosaccharides, which plays a key role in establishing and maintaining the infant gut microbiota (Bidart et al., 2015). Excreted microvesicles also carry key protein probiotic effectors of L. casei BL23 (Rubio et al., 2017) Consumption of L. casei BL23 modulates the microbiota in favor of Lactobacillaceae, Porphyromonadaceae, and Comamonadaceae (Yin et al., 2014).

To deliver probiotic benefits to the hosts, a stable probiotic product with a high bacterial viability is required (Tripathi and Giri, 2014). L. casei may be consumed under the form of fermented products, such as fermented olives, cheese or fermented milks. In this case, the food matrix plays a critical role in maintaining the viability of probiotics (Silva et al., 2015) and in protecting them from digestive assaults (Gagnaire et al., 2015; Rabah et al., 2018). As an alternative, L. casei may be consumed within probiotic food supplements. In this case, the galenic preparation should be designed to optimize viability, stability and stress tolerance of the probiotic (Broeckx et al., 2016). In this context, dried probiotic powders are favored by industries as active components for storage, transport and formulation (Huang et al., 2017). Probiotic powders are mainly produced by freeze-drying because of the low processing temperature and a maximum bacterial viability. Freeze-drying is, however, a discontinuous process, with growing, harvesting, resuspension, freezing and vacuum drying steps in a batch mode. Moreover, water removal implies to overcome several latent energy state changes (freezing, sublimation), thus leading to a high energy operating cost. By contrast, the spray-drying process, which is tougher toward bacteria, given the thermal and oxidative conditions, is a continuous process with a high productivity and energy operating cost twice to three times lesser than that of freeze-drying. It thus constitutes an alternative method to produce probiotic powders with higher productivity and energy efficiency (Huang et al., 2017). Whenever using freeze or spray drying, maintaining the viability of probiotics in a dry state remains a key challenge. Indeed, even if no strict dose-response effect is established by clinical studies (Ouwehand, 2017), probiotics human doses above 10 billion CFU per day are generally associated with a more significant study outcome (Kligler and Cohrssen, 2008). Digestive. stress tolerance of spraydried probiotics remains a key issue. In this respect, growth and drying conditions can be driven in order to optimize probiotic efficacy (Broeckx et al., 2016; Huang et al., 2017).

Lactobacillus casei does not belong to the thermophilic lactic acid bacteria. It has a low constitutive tolerance toward oxidative stress, but which can be enhanced by habituation (Zotta et al., 2014) or by genetic engineering (Rochat et al., 2006). Several studies sought ways to enhance tolerance toward heat (Yang et al., 2017), acid (Alcántara et al., 2014) and bile salts (Xiong et al., 2017) stress in L. casei. Incubation of L. casei BL23 in milk prior to consumption promotes persistence in the mammalian digestive tract, further evidencing a profound influence of the growth medium on probiotic abilities (Lee et al., 2015a).

In accordance with above-cited studies, we have recently taken advantage of a dairy medium to produce probiotics with enhanced survival during technological and digestive stresses. We first studied the probiotic Propionibacterium freudenreichii. This cheese bacterium grows in Emmental cheese(a Swiss-type cheese) (Thierry et al., 1998), in the cheese aqueous extracts (Gagnaire et al., 2015) and in cheese whey, a side-product of the cheese industry. Interestingly, growth occurs not only in isotonic whey, but also in hyperconcentrated whey (Huang et al., 2016b). Such growth conditions induce accumulation of energy storage compounds, overexpression of stress adaptation proteins and multi-stress tolerance in propionibacteria. This led to the development of a novel process for spray drying of bacteria, using concentrated sweet whey, a by-product of Emmental cheese manufacture, as a "2-in-1" bacterial culture medium and spray drying matrix (Huang et al., 2017). It hence avoids the intermediate operation steps between fermentation and spray drying, resulting in a continuous production pattern and higher energy efficiency. Due to the high dry matter of concentrated sweet whey $(30 \% \mathrm{w} / \mathrm{w})$, this process allows spray-drying in relatively mild conditions with $130-140^{\circ} \mathrm{C}$ inlet temperature and $50-60^{\circ} \mathrm{C}$ outlet temperature, resulting in $100 \% P$. freudenreichii survival rates at both laboratory scale and semi-industrial scale (Huang et al., 2017). We have previously investigated the stress adaptation of $P$. freudenreichii during growth in concentrated sweet whey. The osmoregulation of $P$. freudenreichii in concentrated sweet whey triggers the multistress response of bacteria, thus leading to the cellular tolerance against the extreme industrial spray-drying conditions. In a preliminary investigation, we have shown that $L$. case $i$ BL23 could also be cultivated and dried using the same medium (Huang et al., 2017). However, the molecular mechanisms leading to multi-stress tolerance upon growth in hyperconcentrated whey remained to be investigated in L. casei BL23.

As shown in our previous work, L. casei is a relatively fragile species, compared to P. freudenreichii (Huang et al., 2017). Spray drying of such a fragile but widely commercialized species thus constitutes a challenging goal for both scientific and industrial stakeholders. Therefore, in this current work, the osmoadaptation, and the resulting multitolerance, were 
investigated in L. casei BL23 during growth in the concentrated sweet whey. A spray drying process in industrial condition was also applied to further explore the feasibility of producing osmoadapted $L$. casei via the novel spray drying process. We furthermore compared different concentrations of whey to define optimal conditions.

\section{MATERIALS AND METHODS}

\section{Strains and Pre-culture}

Lactobacillus casei BL23 was provided by UMR1219 MICALIS, (INRA-AgroParisTech, Jouy-en-Josas, France), stored and maintained by the CIRM-BIA Biological Resource Center (Centre International de Ressources Microbiennes-Bactéries d'Intérêt Alimentaire, INRA, Rennes, France). The pre-culture of $L$. case $i$ was prepared routinely by inoculation (1\% inoculum size) of MRS broth and static cultivation at $37^{\circ} \mathrm{C}$ for $16 \mathrm{~h}$.

\section{Bacterial Growth in Sweet Whey}

Growth of $L$. casei in sweet whey medium was performed as described (Huang et al., 2016a). Briefly, sweet whey media were prepared by rehydration of sweet whey powder (Lactalis ingredients, Mayenne, France) in deionized water to obtain the media with final total solids content (TS, w/w) of 5, 10, 20, 30, and $40 \%$, respectively. These culture media were then autoclaved at $100^{\circ} \mathrm{C}$ for $30 \mathrm{~min}$ before inoculation ( $1 \%$ inoculum size) with L. case $i$ from the MRS pre-culture. The inoculated culture media were incubated statically at $37^{\circ} \mathrm{C}$ for $48 \mathrm{~h}$. The growth curve of L. case $i$ in sweet whey was monitored by CFU counting on plates of MRS medium solidified with $10 \mathrm{~g} /$ liter agar.

\section{Stress Challenges}

Lactobacillus casei was cultivated $48 \mathrm{~h}$ in $5,20,30$, and $40 \%$ total solid content sweet whey, as described above. These different cultures were stressed as follows. Heat challenge was applied to $L$. casei by placing $1.2 \mathrm{~mL}$ (in $2 \mathrm{~mL}$ Eppendorf tube) of the $L$. casei sweet whey culture in a water bath at $60^{\circ} \mathrm{C}$ for $10 \mathrm{~min}$, as described previously (Leverrier et al., 2004). Bile salts challenge was performed by adding $1 \mathrm{~g} /$ liter of bile salts (an equimolar mixture of cholate and deoxycholate; Sigma Chemical, St. Louis, MO, United States) in the culture at $37^{\circ} \mathrm{C}$ for $60 \mathrm{~min}$ as described (Leverrier et al., 2003). Acid challenge was performed by re-suspending the $L$. casei cell pellets in MRS broth adjusted to $\mathrm{pH} 2.0$ using $\mathrm{HCl}$, at $37^{\circ} \mathrm{C}$ for $60 \mathrm{~min}$ as described (Jan et al., 2000). The viability of $L$. casei was determined by CFU counting on MRS-agar. As a control, cultures were left untreated at $37^{\circ} \mathrm{C}$ for the same time in order to determine the population corresponding to $100 \%$ survival. Percent survival was calculated by comparing stressed and unstressed cultures at the end of the same time.

\section{Microscopy}

\section{Light Microscopy}

Neisser staining was carried out to observe the polyphosphate granule accumulated in L. casei cells in 5\% and 30\% sweet whey culture according to the procedure by (Alcántara et al., 2014). Bacterial cultures were heat fixed on microscope slides and then covered for $1 \mathrm{~min}$ with a freshly prepared mixture of 1 volume of Neisser's methylene blue solution (Fluka Analytical, France) and 2 volumes of $0.33 \%$ crystal violet solution in $10 \%$ ethanol. Excess dye was absorbed using blotting paper, and the slides were covered for $1 \mathrm{~min}$ with a $0.3 \%$ solution of chrysoidin G solution (Sigma-Aldrich, Saint Quentin Fallavier, France) prior to extensive rinsing with deionized water. The slides were observed on an Olympus BX51 light microscope at a $\times 1,000$ magnification.

\section{Epifluorescence Microscopy}

Polyphosphate granules were also visualized by DAPI $\left(4^{\prime}, 6-\right.$ diamidino-2-phenylindole) staining as previously described by Mukherjee et al. (2015). Briefly, bacteria were washed in McIlvaine's buffer, fixed in $4 \%$ formaldehyde, permeabilized in $0.3 \%$ Triton X-100, and then stained by $20 \mu \mathrm{g} / \mathrm{mL}$ DAPI in the same buffer. The stained cultures were observed on an Olympus BX51 epifluorescence microscope equipped with aUMWU2 fluorescence filter cube (excitation filter, $330-385 \mathrm{~nm}$; emission filter, $480-800 \mathrm{~nm}$ ) and an Olympus plan $100 \times / 1.25$ oil objective.

\section{Transmission Electron Microscopy}

The morphology of L. casei in 5 and 30\% sweet whey culture was visualized by transmission electron microscopy. Briefly, osmolarity of the 5 and $30 \%$ sweet whey culture was firstly quantified by a freezing-point osmometer (Osmomat 030-D, Gonotec, Berlin, Germany). The L casei cell pellets were collected from 5 or $30 \%$ sweet whey culture by centrifugation at $8000 \mathrm{~g}$ for $10 \mathrm{~min}$. These cell pellets were then washed and re-suspended in a saline buffer with the same osmolarity as their previous culture prior to fixation with $2.5 \%$ glutaraldehyde for $3 \mathrm{~h}$. The bacterial pellets were embedded in agar prior to being cut into $1-\mathrm{mm}$ pieces and fixed with $1 \%$ sodium tetroxide for $1 \mathrm{~h}$. The agar pieces were rinsed with cacodylate buffer and dehydrated in ethanol prior to inclusion in Epon-Araldite-DMP30 resin (polymerized at $60^{\circ} \mathrm{C}$ for $48 \mathrm{~h}$ ). Thin sections $(90 \mathrm{~nm}$ ) were cut (Leica ultra-microtome Ultracut E), collected on copper grids, and then stained with uranyl acetate. Samples were observed with a Jeol 1400 electron microscope (Jeol Co. Ltd., Tokyo, Japan), and images were digitally captured with a Gatan Orius camera (Digital Micrograph Software). The bacterial cell diameter and cell wall thickness were then quantified using Image ${ }^{1}$. Cells with clear edge were selected for the measurement. A total of 20 or more cells from each group were measured.

\section{Measurement of Intracellular Glycogen and Trehalose}

The intracellular trehalose and glycogen were quantified for L. casei in the 5 and $30 \%$ sweet whey culture as described previously with slight modification (Huang et al., 2016b). Briefly, L. casei cell pellets were washed twice by PBS and then divided into two parts, one for quantification of $L$. casei cell number

\footnotetext{
${ }^{1}$ https://imagej.nih.gov/ij/
} 
by CFU counting on MRS agar plates, and the other one for quantification of trehalose and glycogen. The latter sample was re-suspended in acetate buffer $(40 \mathrm{mM}, \mathrm{pH} 5.2)$ after washing twice by PBS. The cell suspension was then heat inactivated for $5 \mathrm{~min}$ at $95^{\circ} \mathrm{C}$, and disrupted using zirconium beads in a homogenizer (Bertin Technologies, Toulouse France) prior to centrifugation of cellular debris. The resulting extract was divided into two parts, further digested using amyloglucosidase (from Aspergillus niger [no. 10115; Sigma-Aldrich]) or trehalase (from porcine kidney [no. T8778; Sigma-Aldrich]) for the hydrolysis of glycogen and trehalose, overnight at $57^{\circ} \mathrm{C}$ and $37^{\circ} \mathrm{C}$, respectively. Samples were quickly frozen, and the resulting glucose was quantified using a glucose hexokinase assay kit (Sigma-Aldrich). The results of glycogen and trehalose concentrations were expressed and normalized as the concentration of generated glucose per $10^{10}$ cells (CFU).

\section{Label-Free Proteomics Whole-Cell Protein Extraction and Tryptic Digestion of Proteins}

The whole-cell proteins were extracted as described before (Huang et al., 2016b). L. casei in 5 and 30\% sweet whey cultures were harvested by centrifugation. In order to maximally exclude the influences of sweet whey components, the cell pellets were washed twice by $0.1 \mathrm{M}$ Tris-citrate buffer $(\mathrm{pH}$ 8 , containing $2 \%$ sodium citrate), twice by $0.1 \mathrm{M}$ Tris-EDTA buffer ( $\mathrm{pH} 8$, containing $0.002 \mathrm{M}$ EDTA), and by PBS buffer. Cell pellets were then re-suspended in SDS lysis buffer and frozen for $2 \mathrm{~h}$ prior to sonication and cell lysis using zirconium beads in the homogenizer. The resulting SDS extracts were recovered by centrifugation $\left(21,000 \times g ; 20^{\circ} \mathrm{C} ; 20 \mathrm{~min}\right)$ and then cleaned and quantified using the two-dimensional (2D) clean-up kit (GE Healthcare Bio-Sciences AB, Uppsala, Sweden) and the 2-D quant kit (GE Healthcare Bio-Sciences AB, Uppsala, Sweden), respectively. Tryptic digestion was performed on $100 \mu \mathrm{g}$ proteins from each sample overnight at $37^{\circ} \mathrm{C}$ and stopped with spectrophotometric-grade trifluoroacetic acid (TFA) (Sigma-Aldrich) as described previously (Leverrier et al., 2004). The supernatants containing peptides were then vacuum dried in Speed-Vac concentrator and stored at $-20^{\circ} \mathrm{C}$ until mass spectrometry analysis.

\section{Nano-LC-MS/MS}

Experiments were performed using a nano RSLC Dionex U3000 system fitted to a Q-Exactive mass spectrometer (Thermo Scientific, San Jose, CA, United States) equipped with a nanoelectrospray ion source. A preliminary sample concentration step was performed on a C18 pepMap100 reverse-phase column [C18 column, $300-\mu \mathrm{m}$ inner diameter (i.d.) by $5 \mathrm{~mm}$ length, $5 \mu \mathrm{m}$ particle size, 100 Å pore size; Dionex, Amsterdam, Netherlands]. Peptide separation was performed on a reversed-phase column (PepMap RSLC C18, $75 \mu \mathrm{m}$ i.d. by $250 \mathrm{~mm}$ length, $3 \mu \mathrm{m}$ particle size, $100 \AA$ A pore size; Dionex) with a column temperature of $35^{\circ} \mathrm{C}$, using solvent A [2\% (v/v) acetonitrile, $0.08 \%(\mathrm{v} / \mathrm{v})$ formic acid and $0.01 \%(\mathrm{v} / \mathrm{v})$ TFA in deionized water] and solvent B [95\% (v/v) acetonitrile, $0.08 \%(\mathrm{v} / \mathrm{v})$ formic acid and $0.01 \%(\mathrm{v} / \mathrm{v})$ TFA in deionized water]. Peptides were separated using a gradient of
$5-35 \%$ solvent B over $80 \mathrm{~min}$ followed by 35 to $85 \%$ solvent B over $5 \mathrm{~min}$ at a flow rate of $0.3 \mu \mathrm{L} / \mathrm{min}$. Eluted peptides were directly electro sprayed into the mass spectrometer operating in positive ion mode with a voltage of $2 \mathrm{kV}$. Spectra were recorded in full MS mode and selected in a mass range $250-2000 \mathrm{~m} / \mathrm{z}$ for MS spectra with a resolution of 70,000 at $\mathrm{m} / \mathrm{z} 200$. For each scan, the ten most intense ions were selected for fragmentation. $\mathrm{MS} / \mathrm{MS}$ spectra were recorded with a resolution of 17,500 at $\mathrm{m} / \mathrm{z}$ 200 and the parent ion was subsequently excluded from MS/MS fragmentation for $20 \mathrm{~s}$. The instrument was externally calibrated according to the supplier's instructions.

\section{Protein Identification}

Peptides were identified from the MS/MS spectra using X!Tandem pipeline software (Langella et al., 2017). The search was performed against a database composed of (i) an in-house database composed of major milk and egg proteins derived from www. uniprot.org (207 proteins in total) and (ii) a portion of the UniProtKB database corresponding to $L$. casei $\mathrm{BL} 23^{2}$. Database search parameters were specified as follow: trypsin cleavage was used and the peptide mass tolerance was set to $10 \mathrm{ppm}$ for MS and 0.05 Da for MS/MS. Oxidation of methionine and phosphorylation on threonine, serine and tryptophan were selected as a variable modification. For each peptide identified, a minimum score corresponding to an $e$-value below 0.05 was considered as a prerequisite for peptide validation.

\section{Protein Quantification}

Every peptide identified by tandem mass spectrometry was quantified using the free MassChroQ software (Valot et al., 2011) before data treatment and statistical analysis within the $R$ software ( $\mathrm{R}$ 3.2.2, Project for statistical computing). A specific $\mathrm{R}$ package called 'MassChroqR' was used to automatically filter dubious peptides for which standard deviation of retention time was superior to $40 \mathrm{~s}$ and to regroup peptide quantification data into proteins. Two different and complementary methods of analysis were used, based on peak counting or XIC (eXtracted Ion Current). For peak counting analysis, analysis of variance was performed on proteins with a minimum peak ratio of 1.5 between both culture conditions. Proteins with an adjusted $p$-value $<0.05$ were considered significantly different.

For XIC based quantification, normalization was performed to take into account possible global quantitative variations between LC-MS runs. Peptides shared between different proteins were automatically excluded from the data set as well as peptides present in less than $80 \%$ of samples. Missing data were then imputed from a linear regression based on other peptide intensities for the same protein (Blein-Nicolas et al., 2015). Analysis of variance was used to determine proteins with significantly different abundance between our two culture conditions.

\section{Spray-Drying Application}

Spray drying was performed on a laboratory-scale spray dryer (Mobile Minor ${ }^{\mathrm{TM}}$, GEA Niro, Denmark). L. casei was cultivated

\footnotetext{
${ }^{2}$ http://www.uniprot.org/taxonomy/543734
} 
in 5, 20, and $30 \%$ total solid content sweet whey, as described above. These different cultures ( $1 \sim 21)$ of $L$. casei were agitated for $10 \mathrm{~min}$ prior to delivery to the dryer by a peristaltic pump (520S, Watson-Marlow, France). A two-fluid nozzle with a diameter of $0.8 \mathrm{~mm}$ was used for atomization. The inlet air temperature was fixed at $185^{\circ} \mathrm{C}$. The temperature and relative humidity of outlet air were controlled at $75 \pm 2^{\circ} \mathrm{C}$ and $10 \pm 1 \%$, respectively, by adjusting the feed rate. The bacterial viabilities before and after spray drying were estimated by enumeration on MRS agar plates. The bacterial population and percentage of survival in powders were obtained as described previously (Huang et al., 2016a).

\section{Statistical Analysis}

All the results are presented as mean value with standard deviation. The data were from triplicate samples. The analysis of variance (ANOVA) followed by Tukey's test was performed using $\mathrm{R}$ software with the 'Rcmdr' package ( $\mathrm{R}$ Development Core Team). Differences between mean values were considered significant when $p<0.05$.

\section{RESULTS}

\section{Bacterial Growth in Sweet Whey Media}

The growth curves of L. casei BL23 in sweet whey media are shown on Figure 1A. Sweet whey in the concentration ranging from 5 to $30 \%$ dry matter sustained the growth of L. casei inoculated at $10^{7} \mathrm{CFU} / \mathrm{mL}$ with a stationary phase approximately starting at $12 \mathrm{~h}$ and a final population close to $2 \times 10^{8} \mathrm{CFU} / \mathrm{mL}$, for $5,10,20$, and $30 \%$ sweet whey. However, final population was slightly lower in $40 \%$ sweet whey, close to $10^{8} \mathrm{CFU} / \mathrm{mL}$. L. casei in $30 \%$ sweet whey yielded the highest final bacterial population, among all the cultures. The resulting population was $3 \times 10^{8}$ $\mathrm{CFU} / \mathrm{mL}$, twice that of $5 \%$ sweet whey cultures $(p=0.063,0.071$ and 0.008 at 12,24 , and 48 h respectively).

\section{Bacterial Stress Physiology}

The different L. casei BL23 sweet whey cultures, $48 \mathrm{~h}$ of incubation, were challenged with heat, acid or bile salts stresses, respectively. Culture in hyperconcentration of sweet whey clearly induced multitolerance. At sweet whey concentrations of 5 and $10 \%$, whatever the challenge, percent survival was close to the lower limit of detection (Figures 1B-D). However, L. casei cultured in 20 and 30\% sweet whey displayed an enhanced stress tolerance, in comparison to the isotonic 5\% sweet whey culture. For instance, the survival rates of $L$. casei in $30 \%$ sweet whey culture under heat, acid and bile-salt stress were approximately 80,25 , and $1 \%$, respectively, while the survival rates were only 3 , 0.008 , and $0.005 \%$ in the $5 \%$ sweet whey culture. Survival rates of $L$. casei cultured in $40 \%$ sweet whey were lower than in $30 \%$ sweet whey culture. This result indicates the multi-stress tolerant phenotype of L. casei in the 20 and $30 \%$ sweet whey cultures.

\section{Accumulation of Intracellular Polyphosphate and Sugar}

Accumulation of intracellular inorganic polyphosphate was sought using both Neisser staining and DAPI staining for the
A

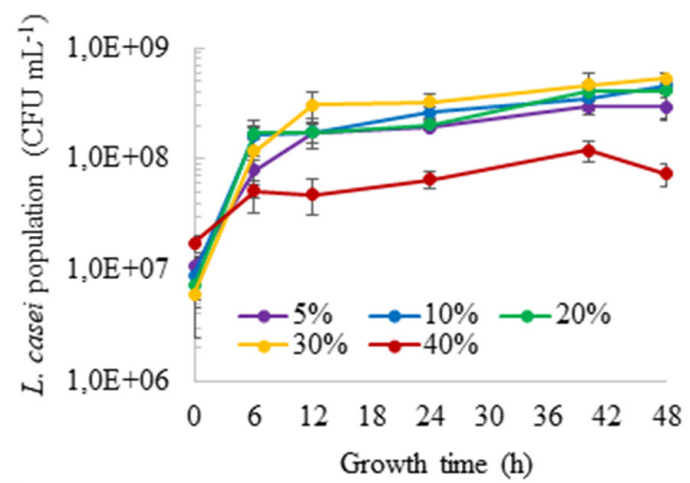

B

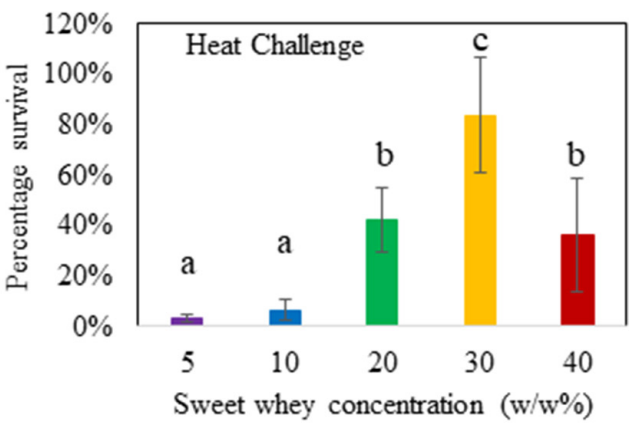

C

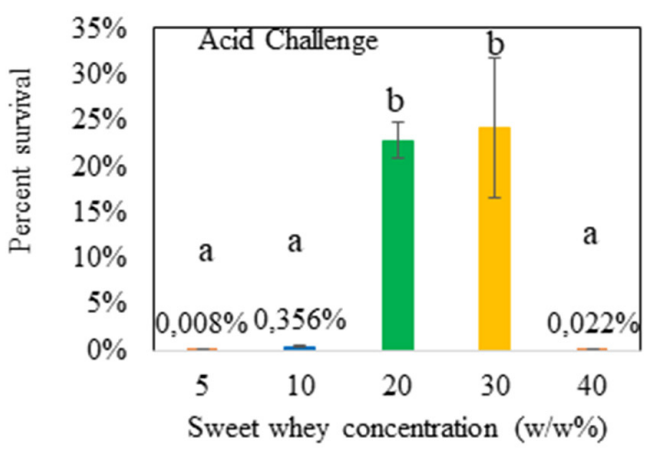

D

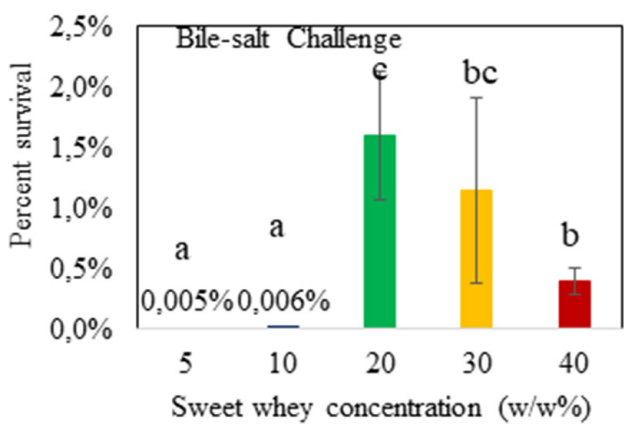

FIGURE 1 | Hyperconcentrated sweet whey culture confers stress tolerance to $L$. casei BL23. Lactobacilli were cultivated $48 \mathrm{~h}$ in sweet whey at different concentrations until stationary phase and their population determined by CFU counting (A). They were then subjected to heat $\left(\mathbf{B}, 60^{\circ} \mathrm{C}\right.$ for $\left.10 \mathrm{~min}\right)$, acid (C, $\mathrm{pH} 2.0$ for $1 \mathrm{~h}$ ) or bile salts (D, $1 \mathrm{~g} / \mathrm{L}$ for $1 \mathrm{~h}$ ) challenge as described in materials and methods. Viable lactobacilli were enumerated by plate counting in treated and control cultures. Results are expressed as percent survival. Error bars represent the standard deviation for triplicate experiments. Different letters above the columns mean significant difference $(p<0.05)$. 

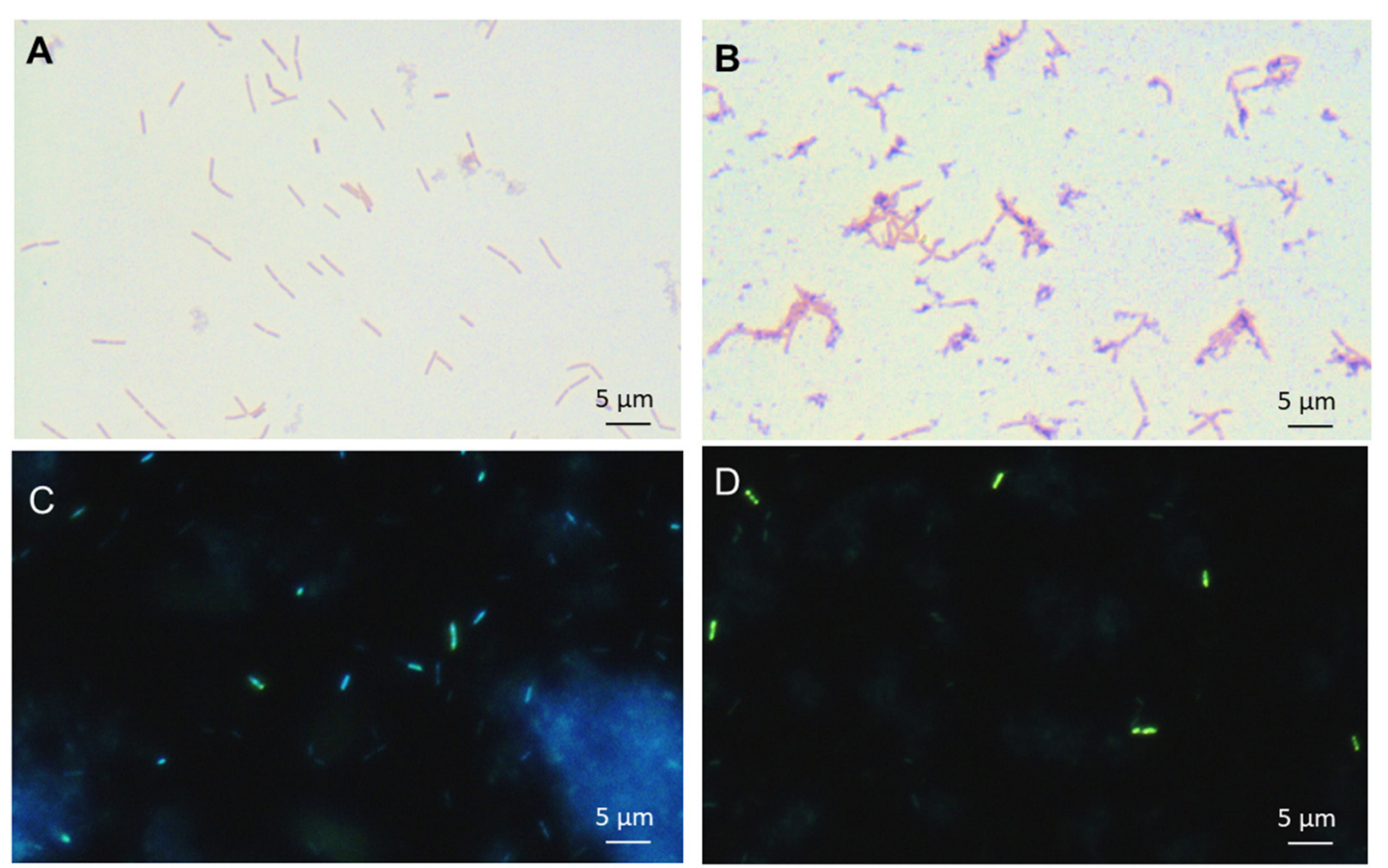

FIGURE 2 | Hyperconcentrated sweet whey triggers intracellular accumulation of polyphosphate granules in L. casei BL23. Lactobacilli were cultivated $48 \mathrm{~h}$ in isotonic 5\% (A,C) or hyperconcentrated 30\% (B,D) sweet whey. Polyphosphate metachromatic granules were evidenced by Neisser staining of fixed culture smears prior to microscopy observation at x1000 magnification (A,B). Polyphosphate was visualized by DAPI staining prior to epifluorescence microscopy (C,D) observation. Green fluorescence indicates cytosolic poly P and blue fluorescence DNA. The scale bar indicates the length corresponding to $5 \mu \mathrm{m}$.

L. casei cells grown in isotonic (5\%) and hyperconcentrated (30\%) sweet whey. Polyphosphate accumulation under the form of dark-stained granules was observed, as reported for various Lactobacillus species using Neisser staining (Alcántara et al., 2014). These dark granules were abundantly observed in the $30 \%$ sweet whey $L$. casei BL23 cultures, yet rarely in 5\% sweet whey cultures (Figures 2A,B). This result was confirmed using DAPI staining. The green fluorescence of bacteria (Figures 2C,D) indicated the abundance of polyphosphate accumulated inside L. casei cells (Mukherjee et al., 2015).

In addition to the accumulation of polyphosphate, the amounts of intracellular trehalose and glycogen were also quantified for the 5 and $30 \% \mathrm{~L}$. casei sweet whey cultures. Glycogen significantly increased $(p<0.05)$ from $11.12($ SD 3.00) to 42.92 (SD6.24) glucose eq. [ $\mu \mathrm{g} / 1010$ cells] when increasing the sweet whey dry matter from 5 to $30 \%$. Accordingly, trehalose increased significantly $(p<0.05)$ from 54.58 (SD 7.63) to 126.14 (SD 27.19) glucose eq. [ $\mu \mathrm{g} / 1010$ cells]. Cells thus accumulated around 4 times more intracellular glycogen and twice more intracellular trehalose, in comparison to $5 \%$ sweet whey cultures.

\section{Characterization of Bacterial Cell Morphology}

Morphology of $L$. casei grown in 5\% sweet whey and 30\% sweet whey was compared using transmission electron microscopy (Figure 3). L. casei cells in 5\% sweet whey (Figures 3A,C) displayed a typical rod shape of lactobacilli. However, the cells in $30 \%$ sweet whey had a distorted morphology (Figures 3B,D) with
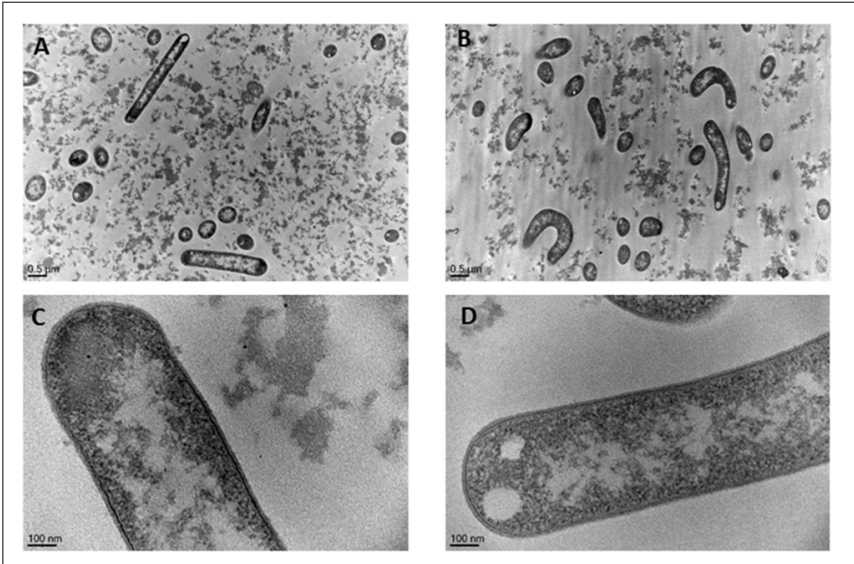

FIGURE 3 | Hyperconcentrated sweet whey triggers morphological rearrangements in L. casei BL23. Lactobacilli were cultivated $48 \mathrm{~h}$ in isotonic $5 \%(\mathbf{A}, \mathbf{C})$ or hyperconcentrated $30 \%(\mathbf{B}, \mathbf{D})$ sweet whey. They were then fixed, stained, and ultrathin sections were observed using transmission electron microscopy. The bacterial cell diameter and cell wall thickness were then quantified. Cells with clear edge were selected for the measurement. 


\section{Upregulation of Proteins in the $30 \%$ Sweet Whey Culture}

The proteomic differential analysis focused on proteins which were overexpressed in $30 \%$ sweet whey, with a minimum ratio of 1.5. A total of 54 proteins were significantly upregulated ( $>1.5$ fold, $P<0.05$ ) in the $30 \% \mathrm{~L}$. casei sweet whey cultures, as compared to the $5 \%$ sweet whey cultures (Supplementary Figure 1). These proteins were categorized according to their biological process and molecular function in Uniprot database, or their metabolism pathways in KEGG classification (Table 1). Among these 54 proteins, 18 proteins $(33.3 \%)$ were involved in the global stress response, including 3 proteins for DNA replication, recombination and repair, one transcription elongation factor, 3 proteins for environmental signal transduction, 4 proteins for oxidative and metal defense, and 7 proteins with chaperone properties.

Apart from the proteins relevant to global stress response, 9 proteins (16.7\%) were involved in carbohydrate metabolisms, including a malolactic enzyme which is only presented in $30 \%$ sweet whey culture. Besides, except the 12 uncharacterized proteins, the other proteins are related to amino acid metabolism, translation and ribosomal structure, phosphate-containing compound metabolism, coenzyme/cofactor biosynthesis, transporter, and cell wall/membrane/envelope proteins.

\section{Application in Spray-Drying}

Multi-tolerance being evidenced, as a result of L. casei BL23 growth in hyperconcentrated sweet whey, we then investigated its tolerance toward spray drying, as this technique is reputed as a severe challenge for bacteria. As shown on Figure 4, survival was close to 0 when L. casei BL23 5\% sweet whey cultures were subjected to spray-drying. However, it was close to $20 \%$ and to $40 \%$ when the same bacterium was cultured in 20 and $30 \%$ dry matter sweet whey, respectively. This indicates a dose-dependent relation between medium concentration and survival rate during spray drying. Accordingly, when cultured in 30\% sweet whey, the BL23 concentration was close to $10^{9} \mathrm{CFU}$ per gram in the resulting powder, while it was close to $10^{7} \mathrm{CFU}$ per gram with $5 \%$ sweet whey cultures.

\section{DISCUSSION}

Lactobacillus casei BL23 is probiotic bacterium which modulates cytokines secretion (Foligné et al., 2007), protects from chemically induced colitis (Rochat et al., 2007), colorectal cancer (Lenoir et al., 2016; Jacouton et al., 2017), or cancer chemotherapy-induced colitis (Cordeiro et al., 2018) in animal models, in accordance with its immunomodulatory ability (Lenoir et al., 2016; Cortes-Perez et al., 2017). Protection toward colitis depends on the dairy delivery matrix in which L. casei BL23 is consumed (Lee et al., 2015b). In addition, a dairy growth medium modulates this potential by enhancing persistence within the digestive tract, in accordance with an enhanced expression of key factors, such as surface proteins, involved in probiotic action (Lee et al., 2015a). Altogether, these data point to the critical role played by the nature of both the growth medium used for industrial production of L. casei BL23, and of the food delivery vehicle used for human consumption. In the present report, we thus investigated the potential of sweet whey, a dairy by-product of pressed cheese manufacture, to produce food-grade dried preparations comprising toughened live cells of L. casei BL23.

This last was shown here to grow on food-grade sweet whey. Industrial whey has already been used as a carrier to dry lactobacilli (Lavari et al., 2017) and other probiotics and food grade bacteria (Huang et al., 2017). However, we show here for the first time that growth of $L$. casei BL23 occurs in sweet whey in a wide range of concentrations, from 5\% dry matter, which is the isotonic concentration, up to $40 \%, 8$ times the isotonic concentration, leading to an osmotic pressure above 50 bar. This suggests efficient adaptation mechanisms leading to yet unrevealed stress tolerance in this bacterium, which is mesophilic and mainly encountered in the digestive tract of mammals. Interestingly, adaptation to the hyperosmotic sweet whey led to the acquisition of tolerance, by a cross-protection induction, toward key stresses encountered during technological and digestive processes (heat, acid, bile salts). These results also suggest that, since BL23 better survives to spray drying process when cultured on $30 \%$ sweet whey, this culture condition prepares the bacterium to the oxidative stress of the spray drying process.

Surprisingly, exposition to salt stress was previously reported to induce alterations in the cell wall of $L$. casei BL23, together with enhanced sensitivity to stressing agents such as mutanolysin, lysozyme, nisin and antibiotics (Piuri et al., 2005; Palomino et al., 2013). Cross protection, and the corresponding mechanisms, thus deserve investigation in osmoadapted L. casei BL23.

Osmoadaptation, i.e., the intracellular readjustments induced by hyperosmotic conditions, is most probably the main stimulus leading to multiple tolerance, as a result of L. casei BL23 growth in hyper concentrated sweet whey. Osmoadapatation has already been shown to induce cross protection toward various stresses in other bacteria (Papadimitriou et al., 2016). However, conflicting results are reported, as a function of the growth medium. As an example, salt adaptation induces tolerance toward bile salts and heat challenge in Enterococcus faecalis (Flahaut et al., 1996), but only in specific conditions. The availability of the osmoprotectant glycine betaine was further shown to drastically affect cross protection in the same bacterium (Pichereau et al., 1999). Not only osmotic stress, but also the nature of accumulated intracellular solutes, determine tolerance acquisition in bacteria (Papadimitriou et al., 2016). We thus investigated known intracellular solutes, generally accumulated under stress adaptation. Indeed, trehalose, glycogen and polyphosphate were accumulated here upon growth in hyperconcentrated sweet whey. Trehalose is a well-known intracellular compatible solute involved in osmoadaptation, but also stored as a reserve compound, mainly in vegetative resting cells, in many bacteria and in yeasts (Argüelles, 2000). In lactobacilli, little is known about its accumulation in response to hyperosmotic stress. However, when exogenously provided, it affords enhanced tolerance of lactobacilli toward heat, cold, dehydration, 
TABLE 1 | Proteins overexpressed after growth in hyperconcentrated 30\% sweet whey, as compared with isotonic 5\% sweet whey.

\begin{tabular}{|c|c|c|c|c|}
\hline Uniprot accession & Description & Ratio 30/5 & $p$-value ${ }^{b}$ & Log (e-value) \\
\hline \multicolumn{5}{|l|}{ Transcription regulation } \\
\hline $\operatorname{tr|B3WF14|B3WF14\_ LACCB~}$ & Transcription elongation factor GreA & 3,03 & $3,2 \mathrm{E}-08$ & -48.4 \\
\hline \multicolumn{5}{|c|}{ Environmental signal transduction } \\
\hline sp|B3WCP4|HPRK_LACCB & HPr kinase/phosphorylase & 1,59 & $2,7 \mathrm{E}-03$ & -7.3 \\
\hline 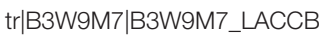 & Similar to universal stress protein, UspA family & 1,92 & $3,7 \mathrm{E}-04$ & -32.2 \\
\hline tr|B3WF83|B3WF83_LACCB & Beta-lactamase-like protein & 2,43 & $3,4 \mathrm{E}-06$ & -9.0 \\
\hline \multicolumn{5}{|c|}{ Oxidative and metal defense mechanisms } \\
\hline $\operatorname{tr|B3WDN3|B3WDN3\_ LACCB~}$ & Conserved protein involved in Fe/S cluster assembly (GN = sufD) & 1,53 & $3,5 \mathrm{E}-03$ & -11.2 \\
\hline 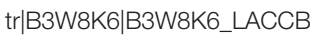 & Oxidoreductase (2,5-diketo-D-gluconic acid reductase) & 1,66 & $7,5 \mathrm{E}-03$ & -71.8 \\
\hline tr|B3W8V4|B3W8V4_LACCB & Possible flavin reductase & 2,22 & $1,9 \mathrm{E}-04$ & -11.4 \\
\hline tr|B3WEZ9|B3WEZ9_LACCB & Aluminum resistance protein & 2,10 & $3,2 \mathrm{E}-05$ & -9.9 \\
\hline \multicolumn{5}{|c|}{ Posttranslational modification, protein turnover, chaperones } \\
\hline sp|B3W9W8|CH10_LACCB & 10 kDa chaperonin (GN = groS) & 1,66 & $6,5 \mathrm{E}-04$ & -118.1 \\
\hline 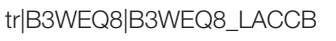 & Protein GrpE & 1,93 & $3,2 \mathrm{E}-06$ & -45.9 \\
\hline sp|B3WEQ7|DNAK_LACCB & Chaperone protein DnaK & 2,29 & $2,4 \mathrm{E}-06$ & -281.7 \\
\hline \multicolumn{5}{|l|}{ Carbohydrate metabolism } \\
\hline tr|B3WC28|B3WC28_LACCB & Malolactic enzyme & $+\infty^{a}$ & $0.2 \mathrm{E}-03$ & -8.5 \\
\hline tr|B3WAP8|B3WAP8_LACCB & L-lactate dehydrogenase & 1,78 & $2,7 \mathrm{E}-03$ & -293.9 \\
\hline $\operatorname{tr|B3WBW7|B3WBW7\_ LACCB}$ & Tagatose-6-phosphate kinase & 2,22 & 4,2E-02 & -23.8 \\
\hline tr|B3WC62|B3WC62_LACCB & Glucose-6-phosphate 1-dehydrogenase & 2,72 & 2,9E-05 & -39.7 \\
\hline tr|B3W7|6|B3W7I6_LACCB & UDP-glucose 4-epimerase (Galactowaldenase) (UDP-galactose 4-epimerase) & 2,88 & $1,7 \mathrm{E}-06$ & -80.1 \\
\hline 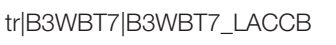 & Glucosamine-6-phosphate deaminase & 3,91 & 8,9E-04 & -96.1 \\
\hline tr|B3WBV8|B3WBV8_LACCB & Aldose 1-epimerase (Mutarotase), GN = galM & 4,40 & $6,5 \mathrm{E}-09$ & -21.2 \\
\hline tr|B3WEKO|B3WEKO_LACCB & Putative 4-oxalocrotonate tautomerase (4-OT) & 3,24 & $2,7 \mathrm{E}-07$ & -27.9 \\
\hline $\operatorname{tr|B3WBW2|B3WBW2\_ LACCB}$ & Phosphotransferase system sugar-specific Ell component & 5,91 & $5,1 \mathrm{E}-08$ & -66.2 \\
\hline \multicolumn{5}{|l|}{ Amino acid metabolism } \\
\hline tr|B3WC99|B3WC99_LACCB & Xaa-His dipeptidase V (Carnosinase) & 1,56 & $5,0 \mathrm{E}-03$ & -25.8 \\
\hline tr|B3WC34|B3WC34_LACCB & Peptidase M3B, oligoendopeptidase F & 1,68 & $1,4 \mathrm{E}-02$ & -13.6 \\
\hline $\operatorname{tr|B3WDM6|B3WDM6\_ LACCB~}$ & Glycine cleavage system $\mathrm{H}$ protein & 1,80 & $1,2 \mathrm{E}-04$ & -21.4 \\
\hline tr|B3W7R6|B3W7R6_LACCB & Cysteine synthase & 2,66 & 8,6E-04 & -347.1 \\
\hline \multicolumn{5}{|c|}{ Nucleic acid metabolism, DNA replication, recombination and repair } \\
\hline 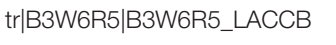 & Single-stranded DNA-binding protein & 1,62 & $7,7 \mathrm{E}-04$ & -36.6 \\
\hline $\operatorname{tr|B3WEH2|B3WEH2\_ LACCB~}$ & Ribonucleoside-diphosphate reductase & 1,97 & $2,4 \mathrm{E}-03$ & -16.4 \\
\hline tr|B3WEH3|B3WEH3_LACCB & Ribonucleoside-diphosphate reductase, beta chain & 2,47 & 8,7E-07 & -21.7 \\
\hline \multicolumn{5}{|c|}{ Translation, ribosomal structure, protein synthesis } \\
\hline sp|B3WF43|RL20_LACCB & $50 S$ ribosomal protein $L 20$ & 1,65 & 2,0E-06 & -14.3 \\
\hline 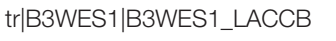 & Proline-tRNA ligase & 1,70 & $1,1 \mathrm{E}-02$ & -18.3 \\
\hline sp|B3WE38|EFTU_LACCB & Elongation factor Tu & 1,73 & $8,5 \mathrm{E}-05$ & -311.3 \\
\hline $\operatorname{tr|B3WEY7|B3WEY7\_ LACCB~}$ & Elongation factor $\mathrm{P}$ & 2,47 & $1,8 \mathrm{E}-05$ & -20.3 \\
\hline sp|B3WES7|EFTS_LACCB & Elongation factor Ts & 5,27 & 1,6E-02 & -95.2 \\
\hline tr|B3WE79|B3WE79_LACCB & 30S Ribosomal protein S1 & 1,98 & $7,3 \mathrm{E}-06$ & -135.9 \\
\hline sp|B3WD58|GATB_LACCB & Aspartyl/glutamyl-tRNA(Asn/Gln) amidotransferase subunit B & 2,07 & $9,3 E-05$ & -33.9 \\
\hline tr|B3WD56|B3WD56_LACCB & Aspartyl/glutamyl-tRNA(Asn/Gln) amidotransferase subunit C & 2,30 & $2,1 \mathrm{E}-05$ & -18.9 \\
\hline sp|B3WES5|RRF_LACCB & Ribosome-recycling factor & 2,75 & $1,7 \mathrm{E}-07$ & -31.6 \\
\hline \multicolumn{5}{|c|}{ Phosphate-containing compound metabolic process } \\
\hline $\operatorname{tr|B3WEB7|B3WEB7/LACCB~}$ & Inorganic pyrophosphatase & 2,90 & $1,6 \mathrm{E}-02$ & -123.1 \\
\hline \multicolumn{5}{|c|}{ Coenzyme/cofactor biosynthesis } \\
\hline 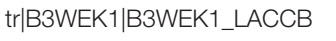 & Putative GTP cyclohydrolase 1 type 2 & 1,95 & $2,7 \mathrm{E}-04$ & -10.2 \\
\hline \multicolumn{5}{|l|}{ Transporter } \\
\hline $\operatorname{tr|B3WDN2|B3WDN2\_ LACCB~}$ & $\mathrm{ABC}$ transporter ATP-binding protein, $\mathrm{GN}=\mathrm{ysfB}$ & 1,89 & $4,2 \mathrm{E}-04$ & -11.6 \\
\hline $\operatorname{tr|B3WDQ6|B3WDQ6\_ LACCB~}$ & Oligopeptide ABC transporter, substrate-binding lipoprotein (GN = oppA) & 2,81 & 2,9E-04 & -9.2 \\
\hline
\end{tabular}


TABLE 1 | Continued

\begin{tabular}{|c|c|c|c|c|}
\hline Uniprot accession & Description & Ratio $30 / 5$ & $p$-value ${ }^{b}$ & $\log (e$-value) \\
\hline \multicolumn{5}{|c|}{ Cell wall/membrane/envelope proteins } \\
\hline 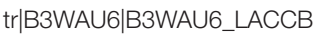 & Putative integral membrane protein yqhA, GN = yqhA & 2,73 & $1,8 \mathrm{E}-07$ & -35.4 \\
\hline tr|B3W7Q5|B3W7Q5_LACCB & Membrane alanine aminopeptidase (pepN) & 2,07 & $8,5 \mathrm{E}-05$ & -28.9 \\
\hline \multicolumn{5}{|l|}{ Function unknown } \\
\hline 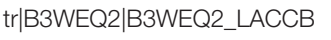 & Putative uncharacterized protein & 1,68 & 1,1E-03 & -27.8 \\
\hline sp|B3W7G6|Y711_LACCB & UPF0145 protein & 1,74 & $9,1 \mathrm{E}-03$ & -21.1 \\
\hline tr|B3WE90|B3WE90_LACCB & Putative uncharacterized protein, GN = LCABL_16100 & 1,81 & 9,5E-03 & -14.4 \\
\hline $\operatorname{tr|B3W7L7|B3W7L7/LACCB~}$ & Putative uncharacterized protein & 1,90 & $6,5 \mathrm{E}-04$ & -14.4 \\
\hline tr|B3WCC5|B3WCC5_LACCB & Putative uncharacterized protein, GN = LCABL_09320 & 1,92 & 2,9E-05 & -13.4 \\
\hline $\operatorname{tr|B3W9N9|B3W9N9\_ LACCB~}$ & Putative uncharacterized protein yfhL & 1,92 & 8,9E-04 & -21.5 \\
\hline 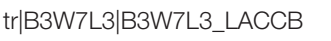 & Putative uncharacterized protein & 1,94 & $1,3 \mathrm{E}-04$ & -13.8 \\
\hline tr|B3W9U7|B3W9U7_LACCB & Putative uncharacterized protein, GN = LCABL_23990 & 2,18 & $6,8 \mathrm{E}-06$ & -4.4 \\
\hline 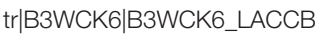 & Uncharacterized protein ywcC & 2,24 & 3,3E-07 & -49.2 \\
\hline tr|B3WA70|B3WA70_LACCB & Putative uncharacterized protein, GN = LCABL_25230 & 2,45 & $6,6 \mathrm{E}-06$ & -30.0 \\
\hline $\operatorname{tr|B3W7M0|B3W7M0\_ LACCB~}$ & Putative uncharacterized protein, GN = LCABL_01870 & 3,38 & 1,3E-08 & -67.6 \\
\hline tr|B3WEG9|B3WEG9_LACCB & Putative uncharacterized protein, GN = LCABL_16890 & 4,10 & $3,1 \mathrm{E}-07$ & -8.3 \\
\hline
\end{tabular}

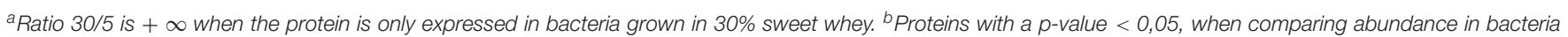
grown in 5\% versus grown in 30\% sweet whey, were considered as significantly different between $5 \%$ and $30 \%$ sweet whey cultures.

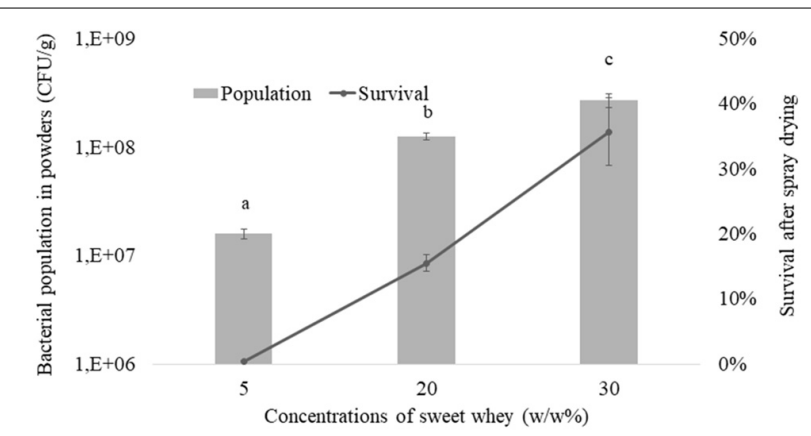

FIGURE 4 | Hyperconcentrated sweet whey improves L. casei BL23 survival during spray drying. Lactobacilli were cultivated 48 hours in isotonic (5\%) or hyperconcentrated (20 and 30\%) sweet whey. These different cultures were then subjected to spray drying. Live cells were then enumerated in the resulting powders upon rehydratation, by CFU counting. Lactobacilli populations, in CFU per gram of powder, were calculated (left ax). Survival, when comparing live populations before and after spray drying, is reported (right ax).

freeze-drying and spray-drying (Bravo-Ferrada et al., 2015; Zheng et al., 2016). Its accumulation within L. casei BL23 cells thus played a role in enhanced multi-tolerance upon growth in hyperconcentrated sweet whey. Glycogen was also accumulated in our conditions. Although it does not affect intracellular osmotic pressure, it plays a role in adaptation. The complete metabolic pathway for glycogen biosynthesis and accumulation, was found in lactobacilli selected species predominantly associated with mammalian and natural habitats, including L. casei. This biosynthesis plays a key role in tolerance toward bile and in probiotic fitness within the digestive tract (Goh and Klaenhammer, 2014). Polyphosphate was also accumulated within cells of $L$. casei BL 23, in the hyperconcentrated sweet whey, yet not in the isotonic one. Accumulation of polyphosphate was already reported in several Lactobacillus species, including casei (Alcántara et al., 2014). As reported by these authors, polyphosphate accumulates within the cytoplasm under the form of granules. This accumulation depends on the availability of elevated concentrations of phosphate in the medium and on the presence of polyphosphate kinase $(p p k)$ gene. It is involved in stress resistance and disruption of $p p k$ leads to reduced survival. Accordingly, polyphosphate storage plays a key role in the thermotolerance of the probiotic L. rhamnosus (Correa Deza et al., 2017). Polyphosphate gained further interest as a beneficial bacterial product, which participates in the maintenance of the gut barrier function by L. casei (Saiki et al., 2016) and by L. brevis (Segawa et al., 2011; Tanaka et al., 2015). This active molecule, derived from L. brevis, was further shown to supress intestinal inflammation and fibrosis in 2 models of induced colitis in mice (Kashima et al., 2015) and to inhibit colon cancer progression, in an animal xenograft model, through induction of cell apoptosis (Sakatani et al., 2016). In our work, the elevated concentrations of calcium-phosphate and of lactose in hyperconcentrated sweet whey are consistent with the observed accumulation of polyphosphate and of carbohydrates.

The proteomic analysis performed here is in agreement with the physiological data. Increase in sweet whey dry matter concentration led to accumulation of key stress proteins involved in bacterial adaptation. This includes proteins known to participate in the repair, protection, and turnover of macromolecules, proteins and nucleic acids. The proteomic signature of L. casei BL23 in hyperconcentrated sweet whey further includes proteins which participate in osmoadaptation. Indeed, over-expression of $o p p A$, encoding an oligopeptide binding protein, confers enhanced resistance to salt, heat and bile stress in L. salivarius (Wang et al., 2015). Proteins involved in oxidative and metal stress remediation were also induced, in accordance with the observed multitolerance. 
Proteins induced in hyperconcentrated sweet whey also included proteins involved in the envelop metabolism, such as yqhA and pepN. Accordingly, we observed modifications in L. casei BL23 morphology, including thinning of the cell wall and curvature of the bacteria in $30 \%$ sweet whey cultures. Thinning of the cell wall, as a result of hyperosmotic adaptation, was already described in L. casei BL23 (Piuri et al., 2005; Palomino et al., 2013), as well as in the soil bacterium Bacillus subtilis. High salt stress modifies its morphology, with a thinner and denser peptidoglycan cell wall in the presence of salt (Palomino et al., 2009). Osmoadaptation, as a result of osmotic stress sensing, indeed results in fluxes of water, which in turn cause modifications in water activity, intracellular volume, turgor pressure, cell wall deformation, and curvature (Morbach and Krämer, 2002).

In accordance with the observed accumulation of general and heat stress proteins such as groS and DnaK, hyperconcentrated sweet whey cultures of $L$. casei BL23 displayed enhanced tolerance to spray-drying. Interestingly, enhancement of the survival rate appeared dose-dependent, as 30\% sweet whey afforded a higher survival than $20 \%$ sweet whey, and $20 \%$ a higher one than $5 \%$. Indeed, the bottleneck of this process is the important heat stress imposed to the bacteria, and oxidative stress due exposure to air stream. Enhanced thermotolerance and accumulation of proteins known to participate in oxidative stress remediation, together with accumulation of protective intracellular compatible solutes, explain the toughness acquired by BL23 cultured in 30\% sweet whey.

Production of dried lactic acid starters and of dried probiotics is a difficult task. It is risky, because of all the abiotic stresses that beneficial bacteria will undergo during drying and subsequent storage. It is compulsory because industrials will more and more ask for high quality dried products, whether as fermentation starters, or as probiotic ingredients. Indeed, the expected stability of live bacteria in the dried product should afford a loss of viability below $0.5 \mathrm{log}$ during a 1 -year storage at $25^{\circ} \mathrm{C}$ (personal communication from stakeholders of the probiotic industry). Culture conditions, pre-treatments, drying media and drying processes should favor the development of tolerance toward technological stresses related to drying and storage. They should also maximize tolerance toward digestive stresses, in probiotic applications. Both freeze-drying and spray-drying processing schemes should thus be improved in this aim. In the present work, we propose a new process, which improves L. casei BL23 stress survival through an osmo-induced multitolerance:

\section{REFERENCES}

Aktas, B., Wolfe, T. J. D., Safdar, N., Darien, B. J., and Steele, J. L. (2016). The impact of Lactobacillus casei on the composition of the cecal microbiota and innate immune system is strain specific. PLoS One 11:e0156374. doi: 10.1371/ journal.pone. 0156374

Alcántara, C., Blasco, A., Zúñiga, M., and Monedero, V. (2014). Accumulation of polyphosphate in Lactobacillus spp. and its involvement in stress resistance. Appl. Environ. Microbiol. 80, 1650-1659. doi: 10.1128/AEM.03997-13

Argüelles, J. C. (2000). Physiological roles of trehalose in bacteria and yeasts: a comparative analysis. Arch. Microbiol. 174, 217-224. doi: 10.1007/ s002030000192 this probiotic is thus prepared for both technological and digestive stresses. The use of a food-grade medium avoids harvesting and washing steps. The high osmolarity of dairy industry side-products triggers multitolerance. Its low water content reduces the need for energy. As a perspective, such a multitolerance induction by hyperconcentrated growth media could also improve survival during freeze-drying. As an alternative, hyperconcentrated food-grade media of vegetal origin, such as soy milk, can be used in a vegetarian option. Altogether, this work opens new perspectives for the industrial production of probiotics reputed as fragile bacteria, such as L. casei BL23.

\section{AUTHOR CONTRIBUTIONS}

SH, FG, CC, and JJ performed the experiments. YLL, RJ, and XC supervised the work. All the authors participated in the writing of the paper.

\section{FUNDING}

$\mathrm{SH}$ got a Ph.D. grant from Agrocampus Ouest and Soochow University and FG from Bioprox.

\section{ACKNOWLEDGMENTS}

The authors sincerely thank the joint Ph.D. project between Agrocampus Ouest and Soochow University. FG is the recipient of a Ph.D. thesis fellowship, co-financed by The French National Association of Research and Technology and by Bioprox. They thank Marie-Bernadette Maillard, Paulette Amet, and Jessica Musset for their excellent technical support. They thank Jessica Bécout and Tommy Moleth for useful discussions.

\section{SUPPLEMENTARY MATERIAL}

The Supplementary Material for this article can be found online at: https://www.frontiersin.org/articles/10.3389/fmicb. 2018.02548/full\#supplementary-material

FIGURE S1 | The figure shows the abundance ration for the selected proteins. Proteins with a ration below 1.5 (0.18 in log 10 scale) were not taken into account.
Bäuerl, C., Pérez-Martínez, G., Yan, F., Polk, D. B., and Monedero, V. (2011). Functional analysis of the p40 and p75 proteins from Lactobacillus casei BL23. J. Mol. Microbiol. Biotechnol. 19, 231-241. doi: 10.1159/0003 22233

Bidart, G. N., Rodríguez-Díaz, J., and Yebra, M. J. (2015). The extracellular wallbound $\beta$-N-Acetylglucosaminidase from Lactobacillus casei is involved in the metabolism of the human milk oligosaccharide Lacto-N-Triose. Appl. Environ. Microbiol. 82, 570-577. doi: 10.1128/AEM.02888-15

Blein-Nicolas, M., Albertin, W., da Silva, T., Valot, B., Balliau, T., MasneufPomarède, I., et al. (2015). A systems approach to elucidate heterosis of protein abundances in yeast. Mol. Cell. Proteomics MCP 14, 2056-2071. doi: 10.1074/ mcp.M115.048058 
Bouchard, D. S., Rault, L., Berkova, N., Le Loir, Y., and Even, S. (2013). Inhibition of Staphylococcus aureus invasion into bovine mammary epithelial cells by contact with live Lactobacillus casei. Appl. Environ. Microbiol. 79, 877-885. doi: 10.1128/AEM.03323-12

Bravo-Ferrada, B. M., Brizuela, N., Gerbino, E., Gómez-Zavaglia, A., Semorile, L., and Tymczyszyn, E. E. (2015). Effect of protective agents and previous acclimation on ethanol resistance of frozen and freeze-dried Lactobacillus plantarum strains. Cryobiology 71, 522-528. doi: 10.1016/j.cryobiol.2015.10.154

Broeckx, G., Vandenheuvel, D., Claes, I. J. J., Lebeer, S., and Kiekens, F. (2016). Drying techniques of probiotic bacteria as an important step towards the development of novel pharmabiotics. Int. J. Pharm. 505, 303-318. doi: 10.1016/ j.ijpharm.2016.04.002

Cordeiro, B. F., Oliveira, E. R., Silva, D. H. S., Savassi, B. M., Acurcio, L. B., Lemos, L., et al. (2018). Whey protein isolate-supplemented beverage, fermented by Lactobacillus casei BL23 and Propionibacterium freudenreichii 138, in the prevention of mucositis in mice. Front. Microbiol. 9:2035. doi: $10.3389 /$ fmicb.2018.02035

Correa Deza, M. A., Grillo-Puertas, M., Salva, S., Rapisarda, V. A., Gerez, C. L., and Font de Valdez, G. (2017). Inorganic salts and intracellular polyphosphate inclusions play a role in the thermotolerance of the immunobiotic Lactobacillus rhamnosus CRL 1505. PLoS One 12:e179242. doi: 10.1371/journal.pone. 0179242

Cortes-Perez, N. G., Lozano-Ojalvo, D., Maiga, M. A., Hazebrouck, S., and AdelPatient, K. (2017). Intragastric administration of Lactobacillus casei BL23 induces regulatory FoxP3 + ROR $\gamma \mathrm{t}+\mathrm{T}$ cells subset in mice. Benef. Microbes 8, 433-438. doi: 10.3920/BM2016.0174

Flahaut, S., Benachour, A., Giard, J. C., Boutibonnes, P., and Auffray, Y. (1996). Defense against lethal treatments and de novo protein synthesis induced by $\mathrm{NaCl}$ in Enterococcus faecalis ATCC 19433. Arch. Microbiol. 165, 317-324. doi: $10.1007 / \mathrm{s} 002030050333$

Foligné, B., Nutten, S., Grangette, C., Dennin, V., Goudercourt, D., Poiret, S., et al. (2007). Correlation between in vitro and in vivo immunomodulatory properties of lactic acid bacteria. World J. Gastroenterol. 13, 236-243. doi: 10.3748/wjg.v13. i 2.236

Gagnaire, V., Jardin, J., Rabah, H., Briard-Bion, V., and Jan, G. (2015). Emmental cheese environment enhances Propionibacterium freudenreichii stress tolerance. PLoS One 10:e0135780. doi: 10.1371/journal.pone.0135780

Goh, Y. J., and Klaenhammer, T. R. (2014). Insights into glycogen metabolism in Lactobacillus acidophilus: impact on carbohydrate metabolism, stress tolerance and gut retention. Microb. Cell Fact. 13:94. doi: 10.1186/s12934-014-0094-3

Hammes, W. P., and Hertel, C. (2006). "The Genera Lactobacillus and Carnobacterium," in The Prokaryotes: Bacteria: Firmicutes, Cyanobacteria, Vol. 4, eds M. Dworkin, S. Falkow, E. Rosenberg, K.-H. Schleifer, and E. Stackebrandt (New York, NY: Springer), 320-403. doi: 10.1007/0-387-30744-3_10

Hill, D., Sugrue, I., Tobin, C., Hill, C., Stanton, C., and Ross, R. P. (2018). The Lactobacillus casei group: history and health related applications. Front. Microbiol. 9:2107. doi: 10.3389/fmicb.2018.02107

Huang, S., Cauty, C., Dolivet, A., Le Loir, Y., Chen, X. D., Schuck, P., et al. (2016a). Double use of highly concentrated sweet whey to improve the biomass production and viability of spray-dried probiotic bacteria. J. Funct. Foods 23 , 453-463. doi: 10.1016/j.jff.2016.02.050

Huang, S., Méjean, S., Rabah, H., Dolivet, A., Le Loir, Y., Chen, X. D., et al. (2017). Double use of concentrated sweet whey for growth and spray drying of probiotics: Towards maximal viability in pilot scale spray dryer. J. Food Eng. 196, 11-17. doi: 10.1016/j.jfoodeng.2016.10.017

Huang, S., Rabah, H., Jardin, J., Briard-Bion, V., Parayre, S., Maillard, M.-B., et al. (2016b). Hyperconcentrated sweet whey, a new culture medium that enhances Propionibacterium freudenreichii stress tolerance. Appl. Environ. Microbiol. 82, 4641-4651. doi: 10.1128/AEM.00748-16

Jacouton, E., Chain, F., Sokol, H., Langella, P., and Bermúdez-Humarán, L. G. (2017). Probiotic strain Lactobacillus casei BL23 prevents colitis-associated colorectal cancer. Front. Immunol. 8:1553. doi: 10.3389/fimmu.2017.01553

Jan, G., Rouault, A., and Maubois, J. L. (2000). Acid stress susceptibility and acid adaptation of Propionibacterium freudenreichii subsp. shermanii. Lait 80, 325-336. doi: 10.1051/lait:2000128

Kashima, S., Fujiya, M., Konishi, H., Ueno, N., Inaba, Y., Moriichi, K., et al. (2015). Polyphosphate, an active molecule derived from probiotic Lactobacillus brevis, improves the fibrosis in murine colitis. Transl. Res. J. Lab. Clin. Med. 166, 163-175. doi: 10.1016/j.trsl.2015.02.002

Klaenhammer, T. R., Kleerebezem, M., Kopp, M. V., and Rescigno, M. (2012). The impact of probiotics and prebiotics on the immune system. Nat. Rev. Immunol. 12, 728-734. doi: $10.1038 /$ nri3312

Kligler, B., and Cohrssen, A. (2008). Probiotics. Am. Fam. Physician 78, 1073-1078. Langella, O., Valot, B., Balliau, T., Blein-Nicolas, M., Bonhomme, L., and Zivy, M. (2017). X!TandemPipeline: a tool to manage sequence redundancy for protein inference and phosphosite identification. J. Proteome Res. 16, 494-503. doi: 10.1021/acs.jproteome.6b00632

Lavari, L., Burns, P., Páez, R., Reinheimer, J., and Vinderola, G. (2017). Study of the effects of spray drying in whey-starch on the probiotic capacity of Lactobacillus rhamnosus 64 in the gut of mice. J. Appl. Microbiol. 123, 992-1002. doi: 10.1111 /jam. 13567

Lee, B., Tachon, S., Eigenheer, R. A., Phinney, B. S., and Marco, M. L. (2015a). Lactobacillus casei low-temperature, dairy-associated proteome promotes persistence in the mammalian digestive tract. J. Proteome Res. 14, 3136-3147. doi: 10.1021/acs.jproteome.5b00387

Lee, B., Yin, X., Griffey, S. M., and Marco, M. L. (2015b). Attenuation of colitis by Lactobacillus casei BL23 is dependent on the dairy delivery matrix. Appl. Environ. Microbiol. 81, 6425-6435. doi: 10.1128/AEM. 01360-15

Lenoir, M., Del Carmen, S., Cortes-Perez, N. G., Lozano-Ojalvo, D., Muñoz-Provencio, D., Chain, F., et al. (2016). Lactobacillus casei BL23 regulates Treg and Th17 T-cell populations and reduces DMH-associated colorectal cancer. J. Gastroenterol. 51, 862-873. doi: 10.1007/s00535-0151158-9

Leverrier, P., Dimova, D., Pichereau, V., Auffray, Y., Boyaval, P., and Jan, G. (2003). Susceptibility and adaptive response to bile salts in Propionibacterium freudenreichii: physiological and proteomic analysis. Appl. Environ. Microbiol. 69, 3809-3818. doi: 10.1128/AEM.69.7.3809-3818.2003

Leverrier, P., Vissers, J. P. C., Rouault, A., Boyaval, P., and Jan, G. (2004). Mass spectrometry proteomic analysis of stress adaptation reveals both common and distinct response pathways in Propionibacterium freudenreichii. Arch. Microbiol. 181, 215-230. doi: 10.1007/s00203-003-0646-0

Maiga, M. A., Morin, S., Bernard, H., Rabot, S., Patient, K. A., and Hazebrouck, S. (2017). Neonatal mono-colonization of germ-free mice with Lactobacillus casei enhances casein immunogenicity after oral sensitization to cow's milk. Mol. Nutr. Food Res. 61: 1600862. doi: 10.1002/mnfr.201600862

Morbach, S., and Krämer, R. (2002). Body shaping under water stress: osmosensing and osmoregulation of solute transport in bacteria. Chembiochem Eur. J. Chem. Biol. 3, 384-397. doi: 10.1002/1439-7633(20020503)3:5<384::AID-CBIC384>3. $0 . \mathrm{CO} ; 2-\mathrm{H}$

Mukherjee, C., Mukherjee, C., and Ray, K. (2015). An improved DAPI staining procedure for visualization of polyphosphate granules in cyanobacterial and microlagal cells. Protoc. Exch. doi: 10.1038/protex.2015.066 [Epub ahead of print].

Muñoz-Provencio, D., Pérez-Martínez, G., and Monedero, V. (2011). Identification of surface proteins from Lactobacillus casei BL23 able to bind fibronectin and collagen. Probiotics Antimicrob. Proteins 3, 15-20. doi: 10.1007/s12602-0119065-8

Ouwehand, A. C. (2017). A review of dose-responses of probiotics in human studies. Benef. Microbes 8, 143-151. doi: 10.3920/BM2016.0140

Palomino, M. M., Allievi, M. C., Gründling, A., Sanchez-Rivas, C., and Ruzal, S. M. (2013). Osmotic stress adaptation in Lactobacillus casei BL23 leads to structural changes in the cell wall polymer lipoteichoic acid. Microbiol. Read. Engl. 159, 2416-2426. doi: 10.1099/mic.0.070607-0

Palomino, M. M., Sanchez-Rivas, C., and Ruzal, S. M. (2009). High salt stress in Bacillus subtilis: involvement of PBP4* as a peptidoglycan hydrolase. Res. Microbiol. 160, 117-124. doi: 10.1016/j.resmic.2008.10.011

Papadimitriou, K., Alegría, Á, Bron, P. A., de Angelis, M., Gobbetti, M., Kleerebezem, M., et al. (2016). Stress physiology of lactic acid bacteria. Microbiol. Mol. Biol. Rev. 80, 837-890. doi: 10.1128/MMBR.00076-15

Pichereau, V., Bourot, S., Flahaut, S., Blanco, C., Auffray, Y., and Bernard, T. (1999). The osmoprotectant glycine betaine inhibits salt-induced crosstolerance towards lethal treatment in Enterococcus faecalis. Microbiology 145, 427-435. doi: 10.1099/13500872-145-2-427 
Piuri, M., Sanchez-Rivas, C., and Ruzal, S. M. (2005). Cell wall modifications during osmotic stress in Lactobacillus casei. J. Appl. Microbiol. 98, 84-95. doi: 10.1111/j.1365-2672.2004.02428.x

Qin, C., Xie, Y., Wang, Y., Li, S., Ran, C., He, S., et al. (2018). Impact of Lactobacillus casei BL23 on the host transcriptome, growth and disease resistance in larval zebrafish. Front. Physiol. 9:1245. doi: 10.3389/fphys.2018.01245

Qin, C., Zhang, Z., Wang, Y., Li, S., Ran, C., Hu, J., et al. (2017). EPSP of L. casei BL23 protected against the infection caused by Aeromonas veronii via enhancement of immune response in zebrafish. Front. Microbiol. 8:2406. doi: $10.3389 /$ fmicb. 2017.02406

Rabah, H., Ménard, O., Gaucher, F., do Carmo, F. L. R., Dupont, D., and Jan, G. (2018). Cheese matrix protects the immunomodulatory surface protein SlpB of Propionibacterium freudenreichii during in vitro digestion. Food Res. Int. 106, 712-721. doi: 10.1016/j.foodres.2018.01.035

Rochat, T., Bermúdez-Humarán, L., Gratadoux, J.-J., Fourage, C., Hoebler, C., Corthier, G., et al. (2007). Anti-inflammatory effects of Lactobacillus casei BL23 producing or not a manganese-dependant catalase on DSS-induced colitis in mice. Microb. Cell Fact. 6:22. doi: 10.1186/1475-2859-6-22

Rochat, T., Gratadoux, J. J., Gruss, A., Corthier, G., Maguin, E., Langella, P., et al. (2006). Production of a heterologous nonheme catalase by Lactobacillus casei: an efficient tool for removal of $\mathrm{H} 2 \mathrm{O} 2$ and protection of Lactobacillus bulgaricus from oxidative stress in milk. Appl. Environ. Microbiol. 72, 5143-5149. doi: 10.1128/AEM.00482-06

Rubio, D., Paula, A., Martínez, J. H., Casillas, M. C. D., Coluccio Leskow, F., and Pérez, O. E. (2017). Lactobacillus casei BL23 produces microvesicles carrying proteins that have been associated with its probiotic effect. Front. Microbiol. 8:1783. doi: 10.3389/fmicb.2017.01783

Saiki, A., Ishida, Y., Segawa, S., Hirota, R., Nakamura, T., and Kuroda, A. (2016). A Lactobacillus mutant capable of accumulating long-chain polyphosphates that enhance intestinal barrier function. Biosci. Biotechnol. Biochem. 80, 955-961. doi: 10.1080/09168451.2015.1135041

Sakatani, A., Fujiya, M., Ueno, N., Kashima, S., Sasajima, J., Moriichi, K., et al. (2016). Polyphosphate derived from Lactobacillus brevis inhibits colon cancer progression through induction of cell apoptosis. Anticancer Res. 36, 591-598.

Segawa, S., Fujiya, M., Konishi, H., Ueno, N., Kobayashi, N., Shigyo, T., et al. (2011). Probiotic-derived polyphosphate enhances the epithelial barrier function and maintains intestinal homeostasis through integrin-p38 MAPK pathway. PLoS One 6:e23278. doi: 10.1371/journal.pone.0023278

Silva, C. C., Domingos-Lopes, M. F., Magalhães, V. A., Freitas, D. A., Coelho, M. C., Rosa, H. J., et al. (2015). Short communication: latin-style fresh cheese enhances lactic acid bacteria survival but not Listeria monocytogenes resistance under in vitro simulated gastrointestinal conditions. J. Dairy Sci. 98, 4377-4383. doi: $10.3168 /$ jds.2015-9420

Souza, R. F. S., Jardin, J., Cauty, C., Rault, L., Bouchard, D. S., Bermúdez-Humarán, L. G., et al. (2017). Contribution of sortase SrtA2 to Lactobacillus casei BL23 inhibition of Staphylococcus aureus internalization into bovine mammary epithelial cells. PLoS One 12:e0174060. doi: 10.1371/journal.pone.0174060
Tanaka, K., Fujiya, M., Konishi, H., Ueno, N., Kashima, S., Sasajima, J., et al. (2015). Probiotic-derived polyphosphate improves the intestinal barrier function through the caveolin-dependent endocytic pathway. Biochem. Biophys. Res. Commun. 467, 541-548. doi: 10.1016/j.bbrc.2015.09.159

Thierry, A., Salvat-Brunaud, D., Madec, M. N., Michel, F., and Maubois, J. L. (1998). Swiss cheese ripening: dynamics of bacterial populations and evolution of the aqueous phase composition for three industrial cheeses. Lait 78, 521-542. doi: 10.1051/lait:1998549

Tripathi, M. K., and Giri, S. K. (2014). Probiotic functional foods: survival of probiotics during processing and storage. J. Funct. Foods 9, 225-241. doi: 10. 1016/j.jff.2014.04.030

Valot, B., Langella, O., Nano, E., and Zivy, M. (2011). MassChroQ: a versatile tool for mass spectrometry quantification. Proteomics 11, 3572-3577. doi: 10.1002/ pmic. 201100120

Wang, G., Li, D., Ma, X., An, H., Zhai, Z., Ren, F., et al. (2015). Functional role of oppA encoding an oligopeptide-binding protein from Lactobacillus salivarius Ren in bile tolerance. J. Ind. Microbiol. Biotechnol. 42, 1167-1174. doi: 10.1007/ s10295-015-1634-5

Xiong, Z.-Q., Wang, Q.-H., Kong, L.-H., Song, X., Wang, G.-Q., Xia, Y.-J., et al. (2017). Short communication: improving the activity of bile salt hydrolases in Lactobacillus casei based on in silico molecular docking and heterologous expression. J. Dairy Sci. 100, 975-980. doi: 10.3168/jds.2016-11720

Yang, Y., Huang, S., Wang, J., Jan, G., Jeantet, R., and Chen, X. D. (2017). Mg2 + improves the thermotolerance of probiotic Lactobacillus rhamnosus GG, Lactobacillus casei Zhang and Lactobacillus plantarum P-8. Lett. Appl. Microbiol. 64, 283-288. doi: 10.1111/lam.12716

Yin, X., Yan, Y., Kim, E. B., Lee, B., and Marco, M. L. (2014). Short communication: Effect of milk and milk containing Lactobacillus casei on the intestinal microbiota of mice. J. Dairy Sci. 97, 2049-2055. doi: 10.3168/jds.2013-7477

Zheng, X., Fu, N., Huang, S., Jeantet, R., and Chen, X. D. (2016). Exploring the protective effects of calcium-containing carrier against drying-induced cellular injuries of probiotics using single droplet drying technique. Food Res. Int. 90, 226-234. doi: 10.1016/j.foodres.2016.10.034

Zotta, T., Ricciardi, A., Ianniello, R. G., Parente, E., Reale, A., Rossi, F., et al. (2014). Assessment of aerobic and respiratory growth in the Lactobacillus casei group. PLoS One 9:e99189. doi: 10.1371/journal.pone.0099189

Conflict of Interest Statement: The authors declare that the research was conducted in the absence of any commercial or financial relationships that could be construed as a potential conflict of interest.

Copyright (C) 2018 Huang, Gaucher, Cauty, Jardin, Le Loir, Jeantet, Chen and Jan. This is an open-access article distributed under the terms of the Creative Commons Attribution License (CC BY). The use, distribution or reproduction in other forums is permitted, provided the original author(s) and the copyright owner(s) are credited and that the original publication in this journal is cited, in accordance with accepted academic practice. No use, distribution or reproduction is permitted which does not comply with these terms. 